\title{
TRANSTORNO ALIMENTAR E CONSTRUÇÃO DE SI NO RELACIONAMENTO PROFISSIONAL-USUÁRIO
}

TRASTORNO DE LA ALIMENTACIÓN Y LA CONSTRUCCIÓN DE SÍ MESMO EN LA RELACIÓN PROFESIONALES-USUARIOS

EATING DISORDER AND SELF CONSTRUCTION IN THE PROFESSIONALPATIENT RELATIONSHIP

\author{
Laura Vilela e Souza \\ Universidade Federal do Triângulo Mineiro, Uberaba/MG, Brasil
}

Manoel Antônio dos Santos

Universidade de São Paulo, Ribeirão Preto/SP, Brasil

\begin{abstract}
RESUMO
O entendimento da Anorexia e Bulimia Nervosa como entidades psicopatológicas legitima algumas versões de si que se impõem aos usuários dos serviços de saúde. O objetivo deste estudo foi compreender de que maneira os diferentes posicionamentos das pessoas diagnosticadas com esses transtornos alimentares constrangem a construção de seus relacionamentos com os cuidadores profissionais. A perspectiva construcionista social fundamentou esta pesquisa. Usuários de um serviço de assistência em transtornos alimentares foram entrevistados individualmente. A análise do material mostrou como o diagnóstico cumpre papel fundamental e, por vezes, único na definição de quem é a pessoa atendida. O conceito do "ser relacional" foi ofertado para que os profissionais de saúde possam pensar a possibilidade de desenharem novos cenários relacionais com o usuário, de modo a incluir a noção de self como movimento, e não estabilidade.
\end{abstract}

Palavras-chave: anorexia nervosa; bulimia; noção de si; construcionismo social.

\section{RESUMEN}

Entender la Anorexia y la Bulimia Nerviosa como entidades psicopatológicas legitima algunas versiones de sí mismos que se imponen a los usuarios de los servicios de salud. El objetivo de este estudio fue entender cómo las diferentes posiciones de las personas diagnosticadas con trastornos de la alimentación limitan la construcción de sus relaciones con cuidadores profesionales. El enfoque del construccionismo social fundamentó el analisis de los datos. El análisis del material mostró cómo el diagnóstico desempeña un papel fundamental, ya veces sólo en la definición de quién es la persona atendida. El concepto de "ser relacional" se ofreció a los profesionales de la salud para pensar la posibilidad de diseñar nuevos escenarios relacionales con el usuario, para incluir la noción de si mismo como un movimiento, no la estabilidad.

Palabras-clave: anorexia; bulimia; sentido de si mismo; construccionismo social.

\begin{abstract}
The understanding of Anorexia Nervosa and Bulimia Nervosa as psychopathological entities approves some self constructions of people in health care services. Our goal in this work was to understand the positioning games of health care service users and how it affects the professional-patient relationship. The social constructionist perspective guided this research. The patients of an assistance service in eating disorders were interviewed. The analysis of the material showed how the diagnosis works to crystallize stigmatizing versions of the patients. The concept of "relational being" was offered for health professionals relational scenarios between professional and patient that could include the concept of self as a movement and not stability.
\end{abstract}

Keywords: anorexia nervosa; bulimia; self construction; social constructionism. 
O entendimento da Anorexia Nervosa (AN) e da Bulimia Nervosa (BN) como entidades psicopatológicas pode legitimar alguns posicionamentos das pessoas diagnosticadas com transtornos alimentares (TA) e convidar a determinadas ações e práticas em saúde. Atualmente, AN é entendida pelos manuais psiquiátricos como um transtorno caracterizado pela recusa na manutenção do peso corporal saudável e a BN como episódios constantes de ingestão excessiva e compulsiva de alimentos, seguida de comportamentos purgativos, como vômito autoinduzido (American Psychiatric Association, 2000). Todavia, outras versões de mundo compartilham espaço com esses sentidos, culminando na crítica à hegemonia da visão biomédica nesse campo (Hepworth, 1999; Malson, 1999). O discurso biomédico, tradicionalmente, aborda as práticas em saúde a partir do foco mantido na doença e sua cura (Souza \& Santos, 2010). Também define o profissional como autoridade absoluta e inconteste em questões de saúde, cabendo ao usuário um lugar de passividade (Pereira \& Almeida, 2005).

Influenciada pelos escritos foucaultianos, Hepworth (1999) entende AN como produto das práticas discursivas sobre feminilidade no Ocidente. Malson e Ussher (1996) propõem que a AN seja entendida "em termos dos discursos e práticas discursivas" (p. 277, tradução nossa) que compõem os entendimentos contemporâneos do que quer que esteja sendo entendido como TA. Malson (1999), por sua vez, defende que a AN não deve ser compreendida como uma patologia individual, mas como "uma coletividade plural de subjetividades corporificadas, experiências e práticas de cuidado ao corpo, embebidas nos e constituídas pelos discursos contemporâneos e práticas discursivas" (p. 137, tradução nossa). Burns (2004) conceitua AN e BN como construções realizadas nas trocas linguísticas e aborda como os discursos de feminilidade estão envolvidos nessas construções. Bordo (1988) entende os fatores sociais não como contribuintes da psicopatologia, mas como constitutivos dela. Krusky (2002) acredita que o que quer que esteja sendo chamado de TA, deve ser entendido a partir do exame de quais crenças os profissionais de saúde carregam e no questionamento dos padrões sociais presentes em suas ações e seus possíveis efeitos na construção de um relacionamento bom ou insatisfatório com o usuário.

Eivors, Button, Warner e Turner (2003) questionam em que medida as teorias atuais acerca de quem seriam as pessoas com TA colaboram na manutenção dos comportamentos considerados sintomáticos. Hepworth (1999) aponta, em um estudo com profissionais envolvidos no atendimento de pessoas diagnosticadas com AN, alguns exemplos de como a construção das práticas dentro das instituições de saúde pode manter os efeitos do que vai ser considerado patológico. Malson, Finn, Treasure, Clarke e Anderson (2004) argumentam em seu estudo que, para os usuários, os conflitos e a resistência ao tratamento não estão ligados a uma dificuldade em admitir o problema e perceber sua gravidade, como acreditam os profissionais, mas são vinculados a uma relutância em aceitar passivamente a visão patologizante dos profissionais frente a eles.

$\mathrm{Na}$ proposta de um plano de tratamento para os TA, a explicação médica desses transtornos pode predominar em relação às demais práticas discursivas de profissionais e usuários. Todavia, as teorias disponibilizadas pelas feministas e pelos teóricos pós-modernos são também úteis para o entendimento do problema alimentar e, inclusive, para o questionamento da necessidade de um tratamento com o foco na supressão dos sintomas de uma suposta psicopatologia. Poder considerar a coexistência de diferentes versões de mundo é um exercício que possibilita com que as nossas próprias verdades sejam problematizadas (Guanaes, 2006).

A tradição individualista, participante da construção do TA como uma psicopatologia, oferece o sentido de self como estável e passível de ser estudado em sua estrutura e características de funcionamento. Um efeito dessa prática pode ser o "autoempobrecimento" mencionado por Gergen (1997), que é a essencialização de "um único modo de ser no mundo", que seria guiado pela terminologia sintomática do transtorno. Malson et al. (2004), em seu estudo sobre o processo de construção da pessoa diagnosticada com TA, abordam tal aspecto, entendendo como, em diversos momentos, o uso do diagnóstico pode convidar construções de si guiadas por um viés patologizante. A descrição do transtorno com suas características e fatores etiológicos associados é sistematicamente disponibilizada aos usuários dos serviços especializados em TA nas falas dos profissionais, de modo que, anos após receberem a alta do tratamento, ex-usuários narram o início de seus sintomas com o uso quase que exclusivo de repertórios interpretativos disponibilizados pelo discurso biomédico (Hepworth, 1999). Nessa vertente, é pertinente indagar: quais aberturas poderiam ser potencializadas com a exploração dos "discursos e práticas discursivas" que compõem os entendimentos contemporâneos do que quer que esteja sendo entendido como TA? (Malson \& Ussher, 1996). 
Buscando responder a esse questionamento, este estudo teve por objetivo compreender de que maneira as diferentes descrições de si das pessoas diagnosticadas com $\mathrm{AN}$ e BN participam da construção de seus relacionamentos com os profissionais de saúde.

\section{Percurso metodológico}

Contexto de produção de sentidos, critérios de participação e cuidados éticos

Este estudo foi realizado em um ambulatório de assistência em transtornos alimentares de um hospitalescola de uma cidade do interior do Estado de São Paulo. Foram convidadas para participar da pesquisa todas as pessoas com diagnóstico de AN ou BN que, no período de realização das entrevistas (2007/2008), estavam em atendimento no serviço havia pelo menos um ano, de forma a terem um tempo razoável de relacionamento com os profissionais desse local. No momento da pesquisa nenhum homem encontravase em atendimento. Considerando esses critérios de inclusão, 12 mulheres, com idade entre 13 e 45 anos, aceitaram participar da pesquisa. Todas as participantes formalizaram sua anuência mediante assinatura do Termo de Consentimento Livre e Esclarecido. O projeto contou também com a anuência da coordenação do serviço. Foi cadastrado junto à Comissão Nacional de Ética em Pesquisa (CONEP) e aprovado pelo Comitê de Ética em Pesquisa com seres humanos da instituição hospitalar. Foram utilizados pseudônimos para preservar o anonimato das participantes. A pesquisadora responsável era psicóloga do serviço e realizava o atendimento dos familiares.

\section{Construção do corpus de análise}

As participantes foram entrevistadas individualmente, em sala reservada do serviço especializado, seguindo-se um roteiro semiestruturado que abordava diferentes pautas, incluindo o tema de interesse deste estudo. Desse roteiro constavam perguntas sobre como as participantes entendiam o que são os TA, como imaginavam que os profissionais avaliavam o tratamento e se identificavam aspectos positivos no tratamento oferecido e no relacionamento estabelecido com os profissionais.

As entrevistas foram audiogravadas em fitas $\mathrm{K} 7 \mathrm{e}$ MP3. Todas as entrevistas foram transcritas na íntegra e literalmente. Como proposto por Rasera e Japur (2003), as transcrições das entrevistas foram divididas em momentos, considerando para essa divisão os temas que estavam sendo conversados em cada um deles.
Para este estudo, selecionamos para análise apenas as entrevistas e os momentos nos quais o conteúdo da conversa mantida tenha abordado a construção identitária e sua relação com as diferentes formas dos usuários se relacionarem com os profissionais de saúde. Para apresentação ao leitor dos momentos selecionados, preservamos a sequência dos diálogos estabelecidos entre entrevistadora e entrevistada. Quatro participantes abordaram a temática de interesse deste estudo em cinco momentos de suas entrevistas (a participante Catarina abordou essa temática em dois momentos), e o conjunto desse material selecionado compôs nosso corpus de análise.

\section{Perspectivas teórico-metodológicas utilizadas para análise}

A perspectiva construcionista social orientou o desenvolvimento deste estudo. Do ponto de vista teórico-metodológico foram abordadas as práticas discursivas utilizadas para a produção de sentidos sobre o tema investigado (Spink \& Medrado, 2000). Adicionalmente, utilizamos a teoria do posicionamento (Harré \& Van Langenhove, 1999) para a visualizaçãodas construções discursivas de si das participantes. Oconceito de posicionamento referese a um conjunto de atributos pessoais genéricos que constroem nas relações um lugar social específico (Van Langenhove \& Harré, 1999). Distintos lugares ocupados implicam diferentes deveres e direitos das pessoas engajadas nas relações sociais.

\section{Descrição das participantes}

Todos os nomes escolhidos para designar os participantes e profissionais de saúde mencionados durante as entrevistas são fictícios. Estefânia: 23 anos, em atendimento no serviço havia três anos e sete meses, com diagnóstico de BN. Estudante universitária, solteira, oriunda de família de camada social média, morava com os pais. Talia: 19 anos, solteira, em tratamento havia dois anos e meio, com diagnóstico de BN. Cursava o ensino médio, era proveniente de uma família de camada social média baixa e também morava com os pais. No momento da entrevista preparava-se para receber alta do serviço. Catarina: 36 anos, estava sendo atendida havia sete anos e meio, com diagnóstico de BN. Divorciada, tinha uma filha e provinha de uma família de camada social média. Ilda: 45 anos, era acompanhada no serviço havia 12 anos, como diagnóstico de AN. Profissional da saúde, no momento da entrevista estava aposentada por invalidez. Solteira, morava com a mãe. Era oriunda de uma família de camada social média. 


\section{Construindo os resultados a partir das entrevistas realizadas}

\section{Estefânia}

O momento selecionado se iniciou com o questionamento da entrevistadora sobre o que era significativo no relacionamento de Estefânia com os profissionais da equipe:

Entrevistadora: Ô, Estefânia, o que que aconteceu de melhor na relação com esses profissionais? Assim, se você fosse pontuar quais as coisas que são significativas pra você?

Estefânia: Eles... Às vezes, eles... Porque é igual eu te falei, vou reforçar, o anoréxico e o bulímico é mentiroso. Eu não sou, eu já fui muito, mas eu não sei mentir mais. Então, às vezes, eu acho assim, o profissional que está me atendendo, ele sabe que eu sou uma bulímica, então talvez ele tenha uma desconfiança de que eu esteja mentindo.

Em resposta à pergunta da entrevistadora, Estefânia posicionou-se como diferente de outras pessoas a quem é designado o diagnóstico de AN ou $\mathrm{BN}$, a partir da distinção entre uma característica que essas demais pessoas possuiriam e que ela já não possuiria mais, que era o hábito de mentir. Tal posicionamento abriu espaço para uma construção de si que definia Estefânia como uma pessoa não mais adoecida ao se comparar com as demais usuárias do serviço. Considerando o contexto de produção dessa entrevista, Estefânia havia mencionado seu sonho de ter alta do serviço para poder, ao concluir seu curso de graduação, ser contratada como profissional da equipe que no momento a assistia. Assim, ao se posicionar como "não mais doente", poderia favorecer uma versão de si capaz de tornar exequível esse plano de futuro.

Ainda que Estefânia pudesse operar essa transformação na forma de se posicionar, os profissionais foram posicionados como aqueles que impediam que ela fosse considerada de forma diferente das demais pessoas diagnosticadas com BN. Nesse momento, ter o diagnóstico de BN adicionado à sua pessoalidade era sinônimo de ser detentora de todas as características desviantes que descrevem tal psicopatologia. A voz dos profissionais pode ser entendida, no fragmento de fala recortado, como a voz do discurso universalizante, próprio da construção dos TA como categorias diagnósticas que definem pessoas com supostas semelhanças entre si (Souza \& Santos, 2007). Evitar identificar-se a partir dessas características seria uma forma de Estefânia demandar que não queria ser vista a partir desse lugar depreciativo, evitando a essencialização de uma pessoalidade desviante.

\section{$\underline{\text { Talia }}$}

O momento selecionado para análise se iniciou com a pergunta da entrevistadora sobre como foi, o que sucedeu, quando Talia recebeu o diagnóstico de AN pela primeira vez:

Entrevistadora: É, deixa eu ver [olhando para o roteiro de perguntas]. Ah tá, quando você primeiro pensou, percebeu, ou alguém te falou que você tinha anorexia, né? $\dot{E}$ um momento normalmente muito dificil, mas o que te ajudou nesse momento, quando você ficou sabendo?

Talia: Eu ria. É, eu olhava pro médico que falava: "É uma coisa que você emagrece, emagrece e você olha no espelho e você tá magra e você tá falando que você tá gorda". [E eu pensava]: "Ai, isso não existe, tá me chamando de louca e louca eu não sou. Sou esperta”. Xinguei o moço, xinguei tudo o moço e ainda fui embora. Eu falei que não era daquele jeito, que eu não tava, que eu tava... que eu era gorda e pronto, não existia, não tem cabimento que você se olha no espelho e você tá gorda e os outros tá falando... Isso não existe.

Nesse fragmento, a voz do médico trouxe o que a literatura médica e psicológica na área reiteradamente apresentam como grave distorção da imagem corporal (American Psychiatric Association, 2000). O uso desse repertório interpretativo posicionou Talia como "portadora" de um transtorno mental. Em nossa sociedade, as pessoas diagnosticadas com determinadas psicopatologias podem ser construídas a partir do discurso que marca a diferença entre loucos e normais, em um julgamento de valor no qual a loucura passa a ser vista a partir do estigma que o diagnóstico constrói (Foucault, 1961/1972). Ao responder a esse posicionamento, que a enquadrava como uma jovem enlouquecida, Talia se posicionou como alguém que era "esperta", retirando-se da cena médica. Nesse momento, o problema alimentar, com o sentido de psicopatologia construída a partir do discurso estigmatizante que capturou a loucura, produziu o afastamento entre profissional e usuário.

$\underline{\text { Ilda }}$

O momento selecionado iniciou-se com a pergunta da entrevistadora:

Entrevistadora: Eo que mais te ajudou na internação?

Ilda: Olha, eu acho, assim, é, eu acho que a equipe ajuda muito desde que ela entenda, ela se ponha numa 
postura de entender o comportamento do paciente. Porque muitas vezes, acho que por falta... por inexperiencia, falta de contato com o paciente desse tipo [com transtorno alimentar], eles tratam a gente de uma forma, assim, inadequada. É, como é que eu vou te falar? Eles falam... Eles esquecem que você é racional. Por exemplo, aumentam o volume da dieta e não me avisam, por exemplo. Ai, toma uma conduta qualquer, entra com medicação tal, entra com dieta tanto, tanto, e vai lá e quer instalar, você fala: "Mas como?". Ai eu olho e o volume tá maior, eu falei. "Mas escuta, o combinado não foi tal volume?". Não avisa, ou então acha, assim, por exemplo, que o que você tá sentindo, tipo assim, as crises de ansiedade que a gente tem, e tem muitas, porque a doença da gente envolve muita coisa... Mas, muitas vezes eu tive crises de ansiedade, então você tem os mesmos sintomas de como se você tivesse tendo um infarto ou uma coisa assim, falta de ar, taquicardia, parece que tem um peso no peito, uma coisa ruim, você fica horrivel, você fica muito mal e a pessoa não acredita. Ai chama a residente, a residente vem atender, que você tá mal e falei pras funcionárias: "Não, não tô aguentando, eu vou morrer, tô mal, tô mal; chama alguém pelo amor de Deus". Ai chegou a residente muito assim: "Ah, esse pessoal interna uma crise de ansiedade pra quê? Tá internada porque tá com ansiedade? Nunca vi isso, internar por causa de ansiedade". Ai ela pegou, deu, tinha um ansiolitico lá, pegou, prescreveu e falou: "Ah, dá agora, meio comprimido”, não sei que remédio que é, é o mesmo que um diazepam, não sei o que que é, não lembro mais. Ai me deram. Não foi lá falar nada pra mim.

Posicionar-se ou ser posicionada como alguém que apresenta uma perturbação emocional que requer cuidados específicos, legitimados e defendidos pela literatura científica da área pode ter sido um dos ingredientes da construção de um argumento de validação de um pedido de que a voz do usuário desse serviço pudesse ser considerada nas decisões de condutas a serem tomadas durante o tratamento.

A postura do médico, narrada por Ilda, pode ainda ser compreendida quando tomamos a herança do discurso cartesiano nas práticas em saúde. Pessotti (1996) retomou a história da formação dos estudantes de Medicina ao longo dos séculos e apontou a influência que o pensamento cartesiano teve nessa disciplina para a "desqualificação de saberes que, por não ostentarem base empírica reconhecida, foram relegados ao limbo, ou à margem da florescente "Ciência"' (p. 442). As práticas discursivas no contexto de produção de uma ciência médica passaram a valorizar os conhecimentos derivados de pesquisa empírica rigorosa, com estratégias metodológicas de observação acurada de "objetos concretos", o que, segundo o referido autor, levou o médico a "rejeitar, como ilegítimas, quaisquer questões relativas à subjetividade humana" (p. 442). Um dos efeitos desse modo de entendimento sobre as ações em saúde pode ser a hierarquização da importância relativa da angústia do usuário, a partir da localização da origem de seu incômodo. Sendo assim, uma "crise de ansiedade", como mencionada por Ilda, teria menor importância do que "um sintoma de origem orgânica". Em uma perspectiva positivista, dada a impossibilidade de comprovação empírica do que o usuário está sentindo, no caso dos desconfortos provocados pelos sintomas emocionais, o profissional pode colocar em dúvida tal descrição e entendê-la como produto do "comportamento manipulador" da pessoa diagnosticada com TA.

Esse discurso pode produzir não apenas a cisão do ser humano em dimensões estanques, como a biológica e a psicológica, mas também a separação entre as diversas categorias profissionais que vão se ocupar do cuidado dessas diferentes dimensões. Assim, é possível entender como um médico nutrólogo, por exemplo, possa não se ver como responsável por lidar com a ansiedade que a pessoa diagnosticada com TA estava vivendo durante sua internação. Tal preocupação seria delegada ("terceirizada") para o psicólogo ou psiquiatra, reconhecidos como "profissionais de saúde mental". Essa divisão de funções especializadas pareceu participar da construção da demanda de Ilda de que os diferentes profissionais pudessem compartilhar o conhecimento ampliado sobre os usuários do serviço, para que, nas ações médicas, por exemplo, fosse levado em consideração o estado emocional da pessoa em sofrimento. A partir desses sentidos da AN como uma perturbação que afeta diferentes dimensões da vida da pessoa, Ilda se apresentou como alguém que precisava de um cuidado integral e integrado dos profissionais do serviço.

\section{Catarina (1)}

No momento destacado para análise, Catarina contou da dificuldade que sentia em virtude da mudança constante de profissionais que atendem no serviço:

Catarina: $O$ que mais me mata aqui no [nome do hospital], é você contar sempre a mesma história.

Entrevistadora: Quando muda o profissional? [devido à rotatividade dos profissionais]

Catarina: É o que me crucifica, aquilo, nossa. É muito ruim você contar aquilo que te faz mal muitas vezes, porque tem muitas vezes em que você conta aquilo que te faz mal. Ele te faz mais mal ainda, mas o pior é quando você tem coragem de falar uma coisa pra alguém e aí aquela pessoa tá com a sua história 
e ela muda, vem outra, você tem que passar tudo aquilo de novo pra contar sua história pra aquela outra, que você sabe que vai mudar, que vai vir outra. Então aquilo nunca tem fim, então você acha que o seu problema nunca tem solução, porque você dá pra ele e ele leva embora o seu problema e não te deixou solução, ele levou com ele o que você contou, essa é a impressão que dá, que ele levou com ele tudo o que você passou pra ele, mas não te deixou solução de nada, não te deixou resolução de nada, não te sarou de nada.

Em sua pergunta, a entrevistadora posicionou Catarina como alguém que não obtinha apoio suficiente dos médicos. Nesse momento, a entrevistadora acompanhava Catarina na contraposição a um posicionamento muito comum no âmbito das práticas discursivas em saúde, que é o do usuário como objeto de intervenção profissional e não como participante ativo na construção do tratamento (Camargo-Borges, Mishima \& McNamee, 2008). No uso desse discurso, a busca por um melhor relacionamento com o profissional pode acontecer a partir da posição denunciativa do usuário. É a partir dessa postura crítica que a entrevistadora convidou Catarina a falar sobre o que poderia ser melhorado em sua relação com os médicos do serviço. Em sua resposta, a participante mencionou seu relacionamento não apenas com os profissionais do serviço, mas também de outros ambulatórios que ela frequentava na instituição hospitalar, incluindo o Ambulatório de Psiquiatria.

Catarina contou de seu desconforto com a rotatividade de profissionais nos ambulatórios do hospital de ensino, por ter que contar a "mesma história" a cada novo membro da equipe que passava a atendêla. O ter de "contar sempre a mesma história" parecia estar relacionado com a descrição de si valorizada no contexto hospitalar. O lugar do usuário pode implicar, dadas as práticas discursivas em saúde, o espaço daquele que deve dissertar sobre suas dores, desconfortos, fraquezas, dificuldades e doenças (Guanaes, 2006). Constrói-se aí o imperativo da confissão (Foucault, 1961/1972). Essas são as narrativas que buscam responder ao entendimento socialmente construído do profissional como o responsável pelo diagnóstico e tratamento dessas dificuldades. No campo das práticas de atendimento a pessoas diagnosticadas com TA, as narrativas muitas vezes valorizadas são aquelas que remetem aos aspectos das dificuldades encontradas na esfera do comportamento alimentar, incluindo, por exemplo, a história da origem dos sintomas.

O sentido produzido do relacionamento entre profissional e usuário como de um espaço compartilhado para uma escuta única e exclusiva do sofrimento humano exigiria a revelação compulsória dessas histórias aos profissionais, devido ao compromisso com um discurso científico que apregoa que apenas por meio do conhecimento dessas narrativas seria possível produzir a "verdade" da pessoa que busca ajuda profissional. Essa produção consistiria, basicamente, no ato de diagnosticar o problema e propor seu tratamento. É a partir de uma perspectiva realista que o TA passa a demandar estratégias para seu reconhecimento e tratamento pelo especialista. Posicionado como responsável por dar conta dessa demanda, o profissional seria aquele que deveria, nas palavras de Catarina, "deixar a solução" para o usuário antes de se retirar de cena. Esse sentido outorgado ao profissional como especialista, segundo ela, produzia um duplo efeito: o sofrimento do usuário de ter que reiterar sua história ad infinitum e o fato de o problema permanecer sem solução.

\section{Catarina (2)}

Interessada em conhecer outros exemplos que Catarina poderia contar sobre relações significativas com os profissionais do serviço, a entrevistadora indagou:

Entrevistadora: Você fala da relação com a sua psicóloga e da relação com o coordenador do grupo de pacientes. Tem algum outro profissional, você não precisa nem falar o nome se você não quiser. Mas, assim, que outras coisas você acha que são fundamentais nessa postura do profissional ou que outras coisas que ajudam?

Catarina: Que eu acho que a vida é feita assim, pequenas coisas importantes, elas se tornam grandes demais. Então, um dia eu cheguei aqui, tava com uma crise de depressão terrível, tinha tido minha filha não fazia muito tempo e eu ainda tava naquela fase de pensar constantemente em me matar, né? E, e, um dia eu cheguei e tava muito nervosa, fui conversar com uma moreninha que tinha, acho que era Mara [médica do serviço] que ela chamava, não me lembro muito bem. Eu sou péssima pra nome e acho que ela chamava Mara. Ai ela... Eu tava falando pra ela do problema, chorando e eu me sentia muito culpada por tá passando aquele problema, por ter aquele problema e por tá descobrindo uma nova doença [BN], ainda, numa pessoa que não precisava de mais nada. Aí, ela pegou e falou assim pra mim: "Ninguém tá falando que isso é sua culpa, Catarina, isso não é sua culpa, não foi você que causou pra você, isso é uma doença, você não tem culpa de nada". Nossa, você não sabe quantos quilos e quilos e toneladas que ela tirou das minhas costas aquele dia, sabe?

$\mathrm{O}$ sentido da BN como uma "entidade nosológica" que seria "culpa" do usuário, um agravo 
que a própria pessoa "criaria", pode ser entendido a partir de algumas práticas discursivas em saúde nas quais é comum a divisão entre as patologias de etiologia orgânica e as de origem emocional. No uso desse discurso, como mencionado, as psicopatologias são muitas vezes questionadas em sua existência, uma vez que não poderiam ser observadas de maneira direta ou evidenciadas por meio de exames físicos, como acontece no caso de boa parte das patologias orgânicas. Nesse questionamento, os sentimentos e dores podem ser interpretados como algo que a própria pessoa "criou", conforme veiculado pela fala de Catarina. Em outros momentos da entrevista, Catarina mencionou que alguns anos antes havia passado por uma cirurgia bariátrica e que nos meses que se seguiram sentia muita dor no abdômen. Após exames físicos que nada indicavam de errado em seu organismo, os médicos rotularam suas dores como "psicológicas".

$\mathrm{O}$ sentido da $\mathrm{BN}$ como algo que o usuário "inventaria" para se autoflagelar, como apareceu nesse momento da entrevista, poderia estar relacionado à forma como Catarina entendia suas dores no abdômen. Ou seja, relacionando o TA com a descrição que obtivera dos médicos sobre suas dores no abdômen como algo que seria "psicológico", esse sentido produziu, como efeitos, segundo Catarina, autoculpabilização e sentimentos de menos valia.

A partir desse sentido outorgado, a "luta" contra o transtorno seria vã e não valeria a pena, pois seria uma luta contra si mesma. A BN como um tipo de sofrimento que a pessoa "quer" ou "busca" deliberadamente para si pode levar ao entendimento de que sua superação dependeria apenas de um ato de vontade da pessoa. Dessa forma, continuar sofrendo seria uma escolha pessoal. Uma vez que não conseguia deixar de sentir sua dor, Catarina entendeu que deveria mesmo ser "louca" e que por isso "merecia morrer", pois não era digna de estar viva. O sentido da doença como algo que não está sob controle consciente da pessoa atendida, que apareceu na voz da médica Mara, teve um efeito apaziguador, na medida em que parecia "tirar o peso da culpa" que Catarina carregava em relação à responsabilidade sobre aquilo que acontecia a si mesma. Sendo uma "doença", não seria mais uma escolha deliberada. Catarina relacionou esse sentido ofertado pela profissional com o lugar social ocupado pela profissão médica. Trata-se de um lugar de respeitabilidade e prestígio social, a partir do qual a médica fala, assumindo uma posição socialmente considerada como constituída de um saber confiável, seguro e inquestionável, legitimado pelo conhecimento científico e lastreado em uma tradição respeitável.

\section{Psicopatologia e construção de si}

Como "portadoras" de uma psicopatologia, as pessoas diagnosticadas com TA podem ser posicionadas de forma particular nas relações com os profissionais. Seus comportamentos podem ser colocados em dúvida, como no caso das "mentiras" de Estefânia. Seu sofrimento pode ser menosprezado, como no caso do residente que atendeu Ilda em sua crise de ansiedade. E suas dores podem ser compreendidas como algo inexistente, como no caso de Catarina. Um verdadeiro reducionismo da pessoa ao diagnóstico como prática corrente no ambulatório de TA pode ser vislumbrado no relato de Catarina, que se traduz na preferência pelo histórico dos sintomas do transtorno como balizador dos diálogos tecidos entre profissional e usuário. Essa priorização decorre, como já argumentado, da ideia de que essas histórias contam da verdade do que acontece com o paciente e, portanto, são a única via de acesso para sua cura. Como afirma Gergen (2009), as palavras dos profissionais têm um peso simbólico e cultural enorme, e é por ter essa densidade socialmente reconhecida que os usuários aceitam que os profissionais façam perguntas que devassam sua intimidade e que abordem aspectos que são bastante sensíveis para eles. Muitas pessoas procuram um profissional por se encontrarem em cenários relacionais de muito sofrimento. Todavia, a exclusividade dessas narrativas no campo relacional profissional-usuário pode impedir que se possa assumir que a pessoa diagnosticada com TA não carrega apenas repertórios de ações consideradas problemáticas, mas também alternativas que podem ser muito valiosas para promover e encorajar as mudanças que ela deseja (Gergen, 2009).

Como afirmam Gergen e McNamee (2000), quando as categorias diagnósticas são tratadas como neutras, ou seja, como a forma como as coisas são, sem que se considerem os processos sociais que as constituem, a prática diagnóstica pode acontecer sem reflexão. Foucault (1961/1972) conta como o uso do discurso psiquiátrico promoveu a mudança histórica no posicionamento das pessoas consideradas desviantes, deslocando-as da posição de "culpadas" para a posição de "inocentes". O entendimento do desvio também se alterou, passando de castigo divino decorrente de uma incorreção moral para o infortúnio da doença. Se tal transformação discursiva ofereceu um lugar menos suscetível a "barbaridades" no tratamento dos desviantes, como afirma o autor, por outro lado localizou a origem do problema no funcionamento psíquico do indivíduo, sem um questionamento sobre quais são os possíveis padrões de relacionamento 
que interatuam para sustentar as descrições de si estigmatizantes.

$\mathrm{Na}$ entrevista com Catarina, o diagnóstico da BN emergiu como peça fundamental para o alívio de sua culpa, para a aceitação do cuidado da equipe e para melhorar a ideia que a usuária tinha de si mesma. Como afirma Gergen (1997), o diagnóstico de uma psicopatologia pode ser positivo para tornar familiar aquilo que, antes, era estranho e desconhecido, e para que o comportamento socialmente inadequado tenha a possibilidade de ser visto com maior empatia pelas pessoas. Considerando-se os padrões culturais e morais vigentes, muitas vezes é mais vantajoso para uma pessoa ter seus comportamentos alimentares inadequados associados à existência de uma patologia do que como fruto de intencionalidade. Porém, será que ocupar o lugar de doente, com todos os processos sociais de exclusão que tal posição implica, é de fato o único caminho possível para sair de uma condição de culpabilização e desespero, como a narrada por Catarina?

Dada a valorização cultural que as ciências desfrutam e a confiança que as pessoas depositam nos profissionais que as representam, a explicação dos fenômenos por meio do diagnóstico de uma psicopatologia pode trazer a confiança de que o conhecimento científico irá prover ajuda (Gergen \& McNamee, 2000). Todavia, como argumentado na análise das entrevistas, em muitos momentos o foco do profissional no TA, no diagnóstico e no histórico hospitalar do usuário, como no caso de Ilda, o impediu de olhar para aquilo que fugia ao padrão, para o que não se repetia, ou seja, para a exceção.

Em uma proposta construcionista social o convite é dirigido à polissemia que pode surgir da exploração da novidade nos relacionamentos, da abertura para a pluralidade de produções de mundo possíveis. Contrapondo-se a essa multiplicidade, o uso do diagnóstico demanda por unanimidade interpretativa, ou seja, pode não permitir outras formas de narrar o que é que esteja sendo denominado de problema alimentar pelos cânones do discurso biomédico. De que maneira o compromisso com um discurso biomédico pode abrir uma reflexão de como o profissional participa da construção que torna inteligível a ideia de uma patologia e, por conseguinte, a necessidade de sua cura?

Por outro lado, o uso do discurso biomédico pelo profissional pode ser considerado legítimo no esforço de compreensão do que está acontecendo com o usuário. O profissional se utiliza de uma visão representacional ou pictórica da linguagem para estabelecer seus diagnósticos (Gergen, 1997).
Como abordado anteriormente, é partindo dessa visão de linguagem que os profissionais confiam na possibilidade de um acesso indireto - no caso das psicopatologias - ao estudo dos "estados internos" das pessoas, solicitando ao usuário um relato detalhado de seus pensamentos e sentimentos. Como afirma o autor, parte-se de uma crença de que as palavras, nesse sentido, seriam uma via de acesso ao "estado interior" da pessoa. Dessa forma, o profissional trata como real aquilo a que a linguagem parece se referir, garantindo sua existência ontológica.

Por essa lógica, é possível entender a postura de muitos profissionais - mencionados pelas participantes durante as entrevistas - de insistirem que as usuárias percebessem que tinham uma psicopatologia que deveria ser tratada. Ou seja, uma postura ética, nesse sentido, é sinônimo de informar ao outro (usuário) sobre algo que ele desconhece em si mesmo (sua doença). O diagnóstico dá legitimidade, confiança e previsibilidade ao profissional, pela funcionalidade operada dentro de um sistema de categorias no qual os problemas são encaixados, em referência a um quadro teórico-conceitual específico. Nesse sentido, a participação em tradições específicas de linguagem faz com que usuário e profissional compartilhem do anseio de decifrar a natureza do problema e nomeálo (Gergen, 1997), ainda que a partir de repertórios interpretativos distintos.

Como afirma Gergen (1997), acreditar que um conhecimento possa ser objetivo e descrever "as coisas como elas realmente são" pode impedir a reflexão sobre suas origens sociais, sobre quais pessoas são beneficiadas com esse conhecimento e quais são marginalizadas, a quem ele ajuda e quando é útil sua aplicação. Inspirados pelas reflexões do referido autor, poderíamos nos perguntar: para que/quem o diagnóstico de um TA pode ser útil? Longe de buscar respostas passíveis de generalização, há um convite para o questionamento sobre quais cenários relacionais o discurso biomédico pode suscitar e a que diferentes sentidos eles parecem convidar. De que maneira esses cenários podem corresponder a nossos ideais no cuidado em saúde?

Nessa direção, Gergen, Hoffman e Anderson (1996) se questionam: qual o objetivo do diagnóstico? Como trazer o usuário para esse processo sem colocá-lo em uma posição subserviente? Como o diagnóstico pode ser colaborativo? Que outras palavras podem ser utilizadas e com que vantagens? Esses questionamentos podem ser úteis para se pensar o campo de tratamento dos TA, incluindo a questão de quais vozes são incluídas ou suprimidas no processo relacional profissional-usuário e quais possibilidades 
se abrem quando ambos se dão conta de que as categorias diagnósticas podem ser consideradas a partir de suas tradições locais de origem e percebem que existem outras tradições de entendimento possíveis. $\mathrm{Na}$ criação de um plano terapêutico para $\mathrm{AN}$ e BN, os jogos de posicionamentos assumidos pelo profissional e pelo usuário são atravessados pelos padrões culturais de interação disponibilizados para essas posições sociais e pelos repertórios interpretativos considerados apropriados para esse campo relacional. $\mathrm{Na}$ interanimação dialógica produzida, o relacionar-se constrói a pessoa diagnosticada com $\mathrm{AN}$ e BN como alguém.

Por essa razão, ainda que as relações profissionalusuário estejam "marcadas por posições sociais e institucionalmente estabelecidas" (Pinheiro, 2000, p. 187), as negociações com relação a essas posições e sentidos podem acontecer a todo momento. Dessa forma, a possibilidade de mudança na construção de um "eu" participa dessas negociações (Guanaes, 2006). Quando o usuário é questionado sobre qual é o problema, ele é convidado a trazer para a conversa histórias que constroem um problema e ratificam as posições estereotipadas de alguém que pede ajuda a alguém que a oferece. Essas posições predefinidas no discurso dominante solicitam uma coerência narrativa, que pode impedir o acesso à multiplicidade de versões possíveis (Pinheiro, 2000).

A tradição individualista que atravessa as produções diagnósticas entende os indivíduos como entidades autocontidas separadas umas das outras. No modelo biomédico, a pessoa é concebida como separada do meio (familiar e social) e como influenciada por seu contexto de vida. Para Gergen (2009), esse modo de construção identitária pode favorecer uma experiência de impotência ou porque não é possível, muitas vezes, mudar esse meio externo que influencia negativamente o indivíduo, ou porque não é possível mudar um "mundo interno" que estaria funcionando inadequadamente. A própria noção de que caberia à pessoa modificar algo para buscar uma melhor relação consigo mesma e com o mundo é derivada dessa concepção de indivíduo como autocontido, capaz de agir de maneira voluntária e autônoma, garantindo a noção de agência pessoal. Essa construção de si mesmo convida à comparação entre as pessoas e sua categorização entre melhores e piores, capazes e incapazes, doentes e sãos. Além disso, como argumenta Gergen (2009), como não é possível o acesso direto a esse mundo interno alheio, as ações e intenções das pessoas podem ser sempre contestadas, convidando à produção de movimentos relacionais de desconfiança. Para esse autor, essa tradição traz uma visão utilitarista dos relacionamentos, sendo o relacionar-se, em muitos momentos, um esforço que viria na contramão dos interesses individuais.

Que possibilidades discursivas alternativas poderiam evitar a localização do problema em um mundo interno supostamente adoecido da pessoa que busca ajuda? Procuramos encontrar na literatura uma oferta discursiva para pensarmos a noção de self na construção do tratamento dos TA. Uma alternativa é dada por Gergen (2009), que sugere que as ações humanas não precisam necessariamente ser explicadas nem por uma razão localizada internamente, nem por pressão de um evento externo, mas por uma confluência coativa em uma série de relacionamentos mutuamente definidores, dentro dos quais nossa ação se torna inteligível. O conceito de confluência é de difícil definição, uma vez que Gergen (2009) afirma que sua própria existência dependerá de quem o define. Cada tentativa de definição estará situada dentro de uma tradição de relacionamento. Qualquer que seja o recorte que façamos, ele imporá um limite nas nossas formas de compreensão. O conceito do "ser relacional", proposto por esse autor, parte dessa noção e assume que é nos relacionamentos que nos tornamos alguém, que construímos uma identidade. Esse é um conceito utilizado para substituir a noção de um "eu" como uma entidade estática, propondo-se um "ser" que se constitui nas e pelas relações, um ser expresso pelo movimento, algo que se move de um passado para o presente e para um devir. Portanto, a identidade passa a ser vista como dependente dos jogos de posicionamentos nos relacionamentos.

Transpondo esse conceito para as práticas discursivas no campo de construção do tratamento dos TA, pode-se convidar à coexistência um repertório de eus das pessoas diagnosticadas com $\mathrm{AN}$ ou $\mathrm{BN}$, em contraposição a um entendimento único de quem é o usuário, valorizando-se a multiplicidade narrativa. Isso não implica, como alerta Gergen (2009), a exclusão das histórias de déficit produzidas nesse campo relacional, uma vez que qualquer história pode ser considerada fértil levando-se em conta seu uso nos relacionamentos. Todavia, é importante perceber como as histórias, consideradas como ações situadas, podem "sustentar" ou "destruir" relacionamentos, "aproximar" ou "afastar" pessoas e cristalizar "rituais de relação". Essa possibilidade discursiva pode ser uma alternativa oferecida ao sentido do problema alimentar como "fraqueza" ou "frescura", como condutas que a pessoa assumiria para chamar a atenção de quem está ao seu redor, como um gesto intencional ou como algo patológico. Nessa perspectiva, as ações das pessoas diagnosticadas com $\mathrm{AN}$ e $\mathrm{BN}$ passam a ser entendidas como ações conjuntas entre profissional e usuário. 
Considerando-se os posicionamentos assumidos pelas participantes nas entrevistas pudemos analisar, neste estudo, as implicações identitárias e relacionais do diagnóstico de uma psicopatologia. Pensar identidade como parte de processos conversacionais convida, como propõe McNamee (1996), ao questionamento de como as formas de falar sustentam interações específicas, como favorecem determinadas ações e descrições em detrimento de outras. Operar essas reflexões no espaço conversacional profissionalusuário é um convite a pensar novas práticas discursivas para a produção de descrições identitárias no âmbito do tratamento dos TA, favorecendo condições para instaurar um diálogo transformador.

\section{Referências}

American Psychiatric Association. (2000). Diagnostic and statistical manual of mental disorders (rev.). Washington DC: Author.

Bordo, S. (1988). Anorexia nervosa and the crystallization of culture. In I. Diamond \& L. Quinby (Orgs.), Feminism and Foucault: Reflection on resistance (pp. 87-117). Boston: Northeastern University Press.

Burns, M. (2004). Eating like an ox: Femininity and dualistic constructions of bulimia and anorexia. Feminism \& Psychology, 14(2), 269-295.

Camargo-Borges, C., Mishima, S., \& McNamee, S. (2008). Da autonomia à responsabilidade relacional: explorando novas inteligibilidades para as práticas de saúde. Gerais: Revista Interinstitucional de Psicologia, 1(1), 8-19.

Eivors, A., Button, E., Warner, S., \& Turner, K. (2003). Understanding the experience of drop-out from treatment for anorexia nervosa. European Eating Disorders Review, 11(2), 90-107.

Foucault, M. (1972). História da loucura na Idade Média (J. T. Coelho Netto, Trad.). São Paulo: Perspectiva. (Original publicado em 1961)

Gergen, K. J. (1997). Realities and relationships: Soundings in social construction ( $2^{\mathrm{a}}$ ed.). Cambridge: Harvard University Press.

Gergen, K. J. (2009). Relational being: Beyond self and community. New York: Oxford University Press.

Gergen, K. J., Hoffman, L., \& Anderson, H. (1996). Is diagnosis a disaster?: A constructionist trialogue. In F. W. Kaslow (Ed.), Handbook of relational diagnosis and dysfunctional family patterns (pp. 3-18). New York: John Wiley and Sons.

Gergen, K. J. \& McNamee, S. (2000). From disordering discourse to transformative dialogue. In R. A. Neimeyer \& J. D. Raskin (Eds.), Constructions of disorder: Meaningmaking frameworks for psychotherapy (pp. 333-349). Washington: American Psychological Association.

Guanaes, C. (2006). A construção da mudança em terapia de grupo: um enfoque construcionista social. São Paulo: Vetor.

Harré, R. \& Van Langenhove, L. (Eds.). (1999). Positioning Theory. Oxford: Blackwell Publishers.

Hepworth, J. (1999). The social construction of anorexia nervosa. London: Sage Publications.
Krusky, M. (2002). Women and thinness: The watch on the eve of the feast. Therapy with families experiencing troubled eating. Journal of Systemic Therapies, 21(1), 58-76.

Malson, H. (1999). Women under erasure: Anorexic bodies in postmodern context. Journal of Community \& Applied Social Psychology, 9, 137-153.

Malson, H., Finn, D. M., Treasure, J., Clarke, S., \& Anderson, G. (2004). Constructing "the eating disordered patient": A discourse analysis of accounts of treatment experiences. Journal of Community \& Applied Social Psychology, 14(6), 473-489.

Malson, H. \& Ussher, J. M. (1996). Body poly-texts: Discourses of the anorexic body. Journal of Community \& Applied Social Psychology, 6(4), 267-280.

McNamee, S. (1996). Therapy and identity construction in a postmodern world. In D. Grodin \& T. R. Lindlof (Eds.), Constructing the self in a mediated world (pp. 141-155). London: Sage Publications.

Pereira, O. P. \& Almeida, T. M. C. (2005). Saúde e poder: um estudo sobre os discursos hegemônicos e subalternos em contextos multiculturais. Revista Brasileira de Crescimento e Desenvolvimento Humano, 15(2), 91-98.

Pessotti, I. (1996). A formação humanística do médico. Medicina, 29, 440-448.

Pinheiro, O. D. (2000). Entrevista: uma prática discursiva. In M. J. P. Spink (Org.), Práticas discursivas e produção de sentidos no cotidiano: aproximações teóricas e metodológicas (pp. 183-214). São Paulo: Cortez.

Rasera, E. F. \& Japur, M. (2003). Grupo de apoio aberto para pessoas portadoras do HIV: a construção da homogeneidade. Estudos de Psicologia, 8(1), 55-62.

Souza, L. V. \& Santos, M. A. (2007). Anorexia e bulimia: conversando com as famílias. São Paulo: Vetor.

Souza, L. V. \& Santos, M. A. (2010). A participação da família no tratamento dos transtornos alimentares. Psicologia em Estudo (Maringá), 15(2), 285-294.

Spink, M. J. P. \& Medrado, B. (2000). Produção de sentidos no cotidiano: uma abordagem teórico-metodológica para análise das práticas discursivas. In M. J. P. Spink (Org.), Práticas discursivas e produção de sentidos no cotidiano: aproximações teóricas e metodológicas (pp. 41-61). São Paulo: Cortez.

Van Langenhove, L. \& Harré, R. (1999). Introducing positioning theory. In R. Harré \& L. Van Langenhove (Eds.), Positioning Theory (pp. 14-31). Oxford: Blackwell publishers.

\section{Agradecimentos}

Agradecemos à professora Sheila McNamee, da Universidade de New Hampshire, pela colaboração neste trabalho e ao Conselho Nacional de Desenvolvimento Científico e Tecnológico - CNPq Bolsa de Produtividade em Pesquisa do segundo autor.

Submissão em: 08/06/2011

Revisão em: 18/08/2012

Aceite em: 28/08/2012 
Souza, L. V. \& Santos, M. A. (2014). Transtorno alimentar e construção de si no relacionamento profissional-usuário.

Laura Vilela e Souza é Professora do Departamento de Psicologia da Universidade Federal do Triângulo Mineiro (UFTM). Psicóloga, Mestre e Doutora em Psicologia pela Universidade de São Paulo (FFCLRP-

USP). Pesquisadora do Laboratório de Investigações sobre Práticas Dialógicas e Relacionamentos Interpessoais

(PROSA - CNPq). Endereço: Departamento de

Psicologia. Universidade Federal do Triângulo Mineiro -

UFTM. Endereço: Avenida Getúlio Guaritá, 159, $3^{\circ}$ andar. Abadia. Uberaba/MG, Brasil. CEP 38025-440.

E-mail: lauravilelasouza@gmail.com

Manoel Antônio dos Santos é Professor Associado 3 do Departamento de Psicologia da FFCLRP-USP.
Coordenador do Laboratório de Ensino e Pesquisa em Psicologia da Saúde (CNPq). Bolsista de Produtividade em Pesquisa do CNPq - Nível 1B. E-mail: masantos@,ffclrp.usp.br

\section{Como citar:}

Souza, L. V. \& Santos, M. A. (2014). Transtorno alimentar e construção de si no relacionamento profissional-usuário. Psicologia \& Sociedade, 26(2), 506-516. 